\title{
Training in genetics for child and adolescent psychiatrists within a senior registrar training scheme
}

\author{
A. J. Wood
}

The benefits of experience in paedlatric genetics to child psychiatrists are discuseed. Pursuing a special interest within a child poychiatry rotational training scheme is an important way of widening experience in light of the proposed retorms to training for hospltal doctors.

The Calman report (Department of Health, 1993) recommends that speciality training be reduced to seven years. As a senior registrar in child and adolescent psychiatry based at a tertiary paediatrics referral centre, I arranged an attachment with the department of paediatric genetics as a special interest. I should like to describe this experience and recommend this model as a way of broadening training experience in the light of the Calman Report. In-depth knowledge of genetics is not necessary for all consultant child and adolescent psychiatrists but for those interested in paediatric liaison and learning difficulties it is particularly valuable. There are also increasing opportunities for research.

\section{Poychiatry and genetics}

Psychiatric genetics (the study of inherited factors involved in psychiatric and neurological disorders) is a growing speciality. Within both adult and child psychiatry there is an increasing tendency to understand behaviour in terms of the relative importance of heredity v. environment. Both psychiatrists and geneticists are taking more interest in the behaviours of children and adults with diagnosed genetic syndromes. The concept of a 'behavioural phenotype', i.e. those behaviours which are particularly common in individuals affected by a given genetic condition and understood as an expression of the genotype, is gaining acceptance. A series of behavioural phenotypes have now been described for a number of genetic conditions and research in this area is increasing. Child and adolescent psychiatrists should be aware of advances in this field.

\section{The setting}

The University Department of Child and Adolescent Psychiatry is situated within the Royal Manchester Children's Hospital. It operates a district and tertiary referral service. As a trainee child psychiatrist with experience in hospital paediatrics, I found myself working with complex psychiatric cases in which neurodevelopmental, chronic illness and multiple psychological and social factors all contributed to the aetiology. For cases with developmental, psychological and dysmorphic features, yet no medical diagnosis, a referral had often been made for a genetic assessment. Of the few cases which had been referred to the genetics department by a child psychiatrist, none had received a genetic diagnosis. As a liaison exercise, I arranged to 'observe' a geneticist at work with the following objectives: to gain basic skills in dysmorphology and improve the 'hit rate' for referrals from child psychiatry to genetics; to learn about the practice of genetics with a view to appreciating which families need and benefit from the service; and to understand the basic mechanisms of genetic transmission and learn something about research methods in genetics.

$I$ attended two clinics per month in the department of paediatric genetics, over a period of almost two years. The clinic 
sessions took the form of a seminar held by the consultant geneticist (MS) in which cases were discussed and theoretical issues raised, followed by clinical assessments of patients. The clinics were attended by trainees in hospital and community paediatrics and provided a combination of theoretical and practical supervision.

\section{The experience \\ Clinical}

I observed initial assessments of patients and learned about the use of computer assisted differential diagnosis in genetics. Three different databases are in use, 'POSSUM' (Pictures of Standard Syndromes and Undiagnosed Malformations), The London Dysmorphology Database' and 'The Oxford Medical Database of Neurogenetics'. It is suggested that selected clinical features can be fed in and a differential diagnosis. For each disorder there is an outline of the main clinical features, photographs and a list of publications. I became aware of the subtleties and difficulties of making an accurate diagnosis and the skills in communicating this to families. The diagnosis is often a 'best estimate' and needs to come from an expert and be reviewed over time with the accumulation of evidence. I learnt about some of the laboratory investigations available and gained a working model for taking a pedigree and for conducting a detailed physical examination of patients and relatives. During my attachment, I was able to see children with a variety of genetic diagnoses and improve my knowledge significantly. I now have a working model of what cases to refer.

\section{Theory}

I became familiar with the major textbooks and journals used by geneticists. The seminars offered an opportunity for guided reading and study of specific syndromes as well as informal discussion around some of the ethical issues and controversies of the speciality.

\section{Research}

I learnt about research methods in genetics and developed an interest in behavioural phenotypy. I conducted a study of the behavioural and psychiatric aspects of the Noonan syndrome in collaboration with a paediatric colleague interested in studying clinical and haematological aspects. This generated much interest and sharing of experiences within the seminar discussions and a search for behavioural symptoms in patients assessed in the clinics. In addition. I had the opportunity to attend scientific meetings and discuss further ideas for research with colleagues.

\section{Liaison}

My initial agreement with the consultant was to attend the clinic for six months. Over this period, I developed my interest and was offered the opportunity to continue to attend. I developed a role in contributing a psychiatric assessment to selected patients seen in the clinic, and also referred patients from child psychiatry for genetic assessments. One particular 11-year-old boy with symptoms of depression, dysmorphic features and multiple physical symptoms was finally diagnosed as $\mathrm{XYY}$ and Hunter's syndrome. He was jointly managed by the departments of genetics and psychiatry. A joint collaborative model of working was developed between the departments which has been beneficial to both patients and staff.

\section{Conclusions}

The implications for psychiatrists of the Calman Report have been considered by Caldicott (1993). The recommendations for child and adolescent psychiatry are that the first three years of training should lead to a general competence in psychiatry and basic knowledge of child and adolescent psychiatry. and the last four should lead to full expertise in child and adolescent psychiatry. This clearly does not leave time for training in nonpsychiatric specialities. The importance of paediatrics experience for child psychiatrists is well recognised. If such training is to be feasible there is a need for increasing flexibility within rotational training schemes for trainees to spend blocks of time working in nonpsychiatric specialities. Several reports in the Psychiatric Bulletin have described such schemes: Hill (1992) recommends six months' full-time experience in community paediatrics and Burns et al (1994) describe the inclusion of a six month placement in general practice. both as part of a psychiatric rotational training scheme. I have described an alternative model of developing a relationship with a particular department on a sessional basis and 
cultivating a special clinical interest which has been of mutual benefit. This model requires much commitment and flexibility for it to work. Due to rotating between training placements within the same department, I was able to maintain my interest over a relatively long time period. This would have been more complicated had I rotated further afield.

Sub-speciality attachments during training are not new and can add experience without extending the overall length of training. This model lends itself particularly well to child and adolescent psychiatry, which traditionally has taken trainees with previous experience in other specialities such as paediatrics, neurology, general medicine and general practice. A children's hospital is ideally situated for generating a web of reciprocal attachments between departments allowing different specialities to benefit from a sharing of skills and opportunities. I have gained great insights from this experience into the speciality of genetics and the practice of liaison psychiatry which I hope to develop further in the future.

Experience in genetics is relevant to training in child and adolescent psychiatry. It is important for trainees to have the potential to develop special interests within the confines of a rotational training scheme. For this to be possible there need to be open channels of communication between trainees and scheme coordinators and positive working relationships with non-psychiatric colleagues.

\section{Acknowiedgements}

I should like to thank Dr Maurice Super for providing the valuable training experience and for his advice on this paper.

\section{References}

Burns, T., Silver, T., Freeling, P. \& Crisp. A. (1994) General practice training for psychiatrists. Psychiatric Bulletin. 18, 286-288.

CALDICOTT, F. (1993) Response to the Chief Medical Officer's Report on Specialist Training. Psychiatric Bulletin. 17. 577-579.

DEPARTMENT OF HEALTH (1993) Hospital Doctors: training for an uncertain future. The Report of the Working Group on Specialist Medical Training. (Calman Report). London: HMSO.

Hind, P., Dawkins, J., Griffiths, M. A. \& TAlbot, R. (1992) Experience in community child health as part of training in child \& adolescent psychiatry. Psychiatric Bulletin. 16. 355-356.

A. J. Wood, Tutor in Child and Adolescent Psychiatry, Department of Child and Adolescent Psychiatry, Royal Manchester Children's Hospital, Pendlebury, Manchester M27 4HA 